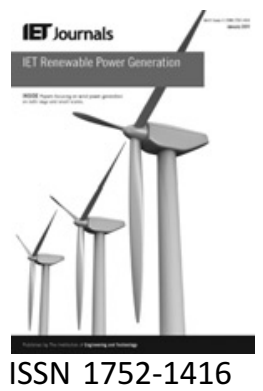

\title{
Coordinated voltage support in distribution networks with distributed generation and microgrids
}

\section{A.G. Madureira J.A.Peças Lopes}

Power Systems Unit of INESC Porto and Faculty of Engineering of Porto University, Rua Dr. Roberto Frias, 378, Porto 4200-465, Portugal

E-mail:agm@inescporto.pt

\begin{abstract}
This paper proposes a new methodology for coordinated voltage support in distribution networks with large integration of distributed generation and microgrids. Given the characteristics of the LV networks, it is shown that traditional control strategies using only reactive power control may not be sufficient in order to perform efficient voltage control. Therefore, microgeneration shedding must also be employed, especially in scenarios with extreme microgeneration penetration. An optimisation tool based on a meta-heuristic approach was developed to address the voltage control problem. In addition, neural networks were employed in order to decrease computational time, thus enabling the use of the tool for online operation. The results obtained revealed good performance of this control approach.
\end{abstract}

\section{Introduction}

Electrical distribution networks have been undergoing significant changes in the last few years due to the growth of distributed generation (DG). Nowadays, due to the restructuring process in electrical distribution systems and the implementation of market structures in several European countries, new business opportunities are arising for DG units. Particularly, the connection of these units to the electric power system brings additional control possibilities to the distribution system operator (DSO), and new technical developments enable DG participation in providing ancillary services such as reserves and voltage support [1].

Usually, DG units are not subject to centralis dispatch and reactive power generation is in most cases restricted by the DSO. Therefore, several changes are required in order to fully profit from the benefits resulting from DG integration, and voltage support emerges as one of the main services to be provided by DG units. This results from the fact that a significant growth of DG penetration will require new operation philosophies in order to exploit reactive power generation capability of DG units, with the objective of optimising network operation, minimising active power losses and maintaining voltage profiles.

Several authors have developed interesting work concerning the impact of DG on voltage control in distribution grids [2-5]. In [6], the authors formulate an algorithm for voltage control in distribution grids with DG by solving an optimisation problem, where active power losses are minimised, subject to a set of technical constraints. The control variables to consider are DG reactive power generation, On-line tap changing (OLTC) transformer settings and capacitor bank settings.

One issue that frequently results from high DG penetration is voltage rise problems, especially in weak distribution networks $[3,7]$. To overcome this problem, it is necessary to control both active and reactive power of the DG units and/or reduce the voltage at the $\mathrm{HV} / \mathrm{MV}$ substation [3].

This voltage rise effect is partly the result of DSO policies based on a 'fit and forget' approach, which also requires DG to operate at a fixed power factor, thus limiting the 
integration of DG and failing to take full profit of DG ability to mitigate such effects $[2,8]$.

In addition, it is expected that a similar phenomenon will take place at the low voltage (LV) side of the distribution system, where microgeneration growth will develop rapidly. The connection of microgeneration to LV networks, creating microgrids, will be playing an important role in future distribution networks. The effects seen at the medium voltage (MV) level may propagate to the LV side with even worse consequences, given the high microgeneration penetration.

To overcome the problems resulting from high DG and microgeneration penetration, an effective control scheme must be developed. Formerly, in conventional systems, voltage control was usually considered as a decentralised control problem. This has mainly to do with the fact that voltage is predominantly a local or regional problem.

However, considering this new operation scenario, a decentralised yet hierarchical voltage control scheme must be envisaged, exploiting communication and control possibilities available for microgrid operation [9].

This paper describes a new tool to be used at the distribution management system (DMS) level in order to manage, in an integrated way, voltage control in $\mathrm{MV} / \mathrm{LV}$ distribution grids in scenarios characterised by large-scale integration of DG, connected at the MV level, and microgeneration, connected at the LV level.

\section{Multi-microgrid system architecture}

A microgrid comprises an LV feeder with several microsources, storage devices and controllable loads connected on the same feeder [10]. These LV microgrids may be operated in interconnected or in islanded mode (under emergency conditions) and are managed by a microgrid central controller (MGCC) that includes several key functions such as economic management and control functionalities $[10,11]$.

The new concept of a multi-microgrid is related to a multilevel structure, existing at the MV distribution level, consisting of LV microgrids and DG units connected on adjacent MV feeders. This concept has been developed within the framework of European project More MicroGrids [12]. Therefore, microgrids, DG units and MV loads under demand side management control can be considered in this network as active cells, for control and management purposes. The technical operation of such a system requires the transposition of the microgrid concept to the MV level, where all these active cells should be controlled by a central autonomous management controller (CAMC) to be installed at the MV bus level of an HV/MV substation. The CAMC will serve as an interface to the DMS and operate under the responsibility of the DSO [9].

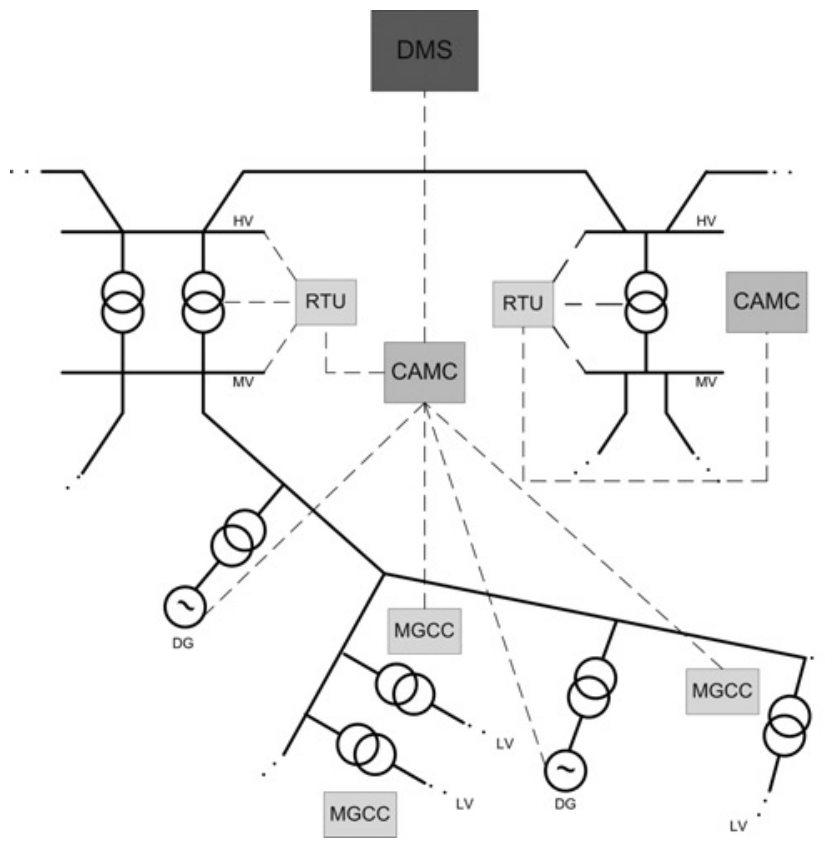

Figure 1 Control and management architecture of a multimicrogrid system

This architecture can be seen in Fig. 1.

Nowadays, the DMS is responsible for the supervision, control and management of the distribution system. In future power systems, in addition to the DMS, there will be new management levels:

- The CAMC, to be housed in HV/MV substations, which will accommodate functionalities that are normally assigned to the DMS (or other new functionalities) and will be responsible for interfacing the DMS with lower level controllers.

- The MGCC, to be housed in MV/LV substations, which will be responsible for managing the microgrid, including the control of the microsources and responsive loads. Voltage monitoring in each $\mathrm{LV}$ grid will be performed using the microgrid communication infrastructure.

Microgrids, together with DG units, will have a significant impact on the electrical distribution system and will enable the participation of these units in providing ancillary services, such as coordinated voltage support.

\section{Voltage control in multi- microgrids}

A hierarchical control system must then be established for voltage control in distribution systems comprising large DG and microgeneration penetration, using communication and control possibilities that will become available in future distribution networks.

The main objective of this voltage control system is to ensure an optimised and coordinated strategy between the 
several voltage levels in the distribution system, namely MV and LV.

As previously mentioned, in extreme situations where there is significant voltage rise due to massive DG and microgeneration penetration, reactive power control is not sufficient to maintain efficient system operation, especially in $\mathrm{LV}$ networks where the $X / R$ index is low. Consider the example system presented in Fig. 2.

Given the example system presented and considering that, in $\mathrm{LV}$ networks, the line resistance is greater than the line reactance (i.e. $R>X$ ), the following expression may be derived from the power flow equations:

$$
P_{\text {inj }}=\frac{V_{2}^{2}}{R}-\frac{V_{2} V_{1}}{R} \cos (\delta)
$$

where $P_{\text {inj }}$ is the active power injected in the MV network, $V_{2}$ is the bus voltage at the $\mathrm{LV}$ network (microgrid), $V_{1}$ is the bus voltage at the MV network, $R$ is the branch resistance and $\delta$ is the angle between $V_{1}$ and $V_{2}$.

According to (1), it may be seen that in order to be able to inject active power $\left(P_{\text {inj }}\right)$ from the LV side (microgrid) to the MV side in resistive networks, voltage should be higher at the $\mathrm{LV}$ bus (i.e. $V_{2}>V_{1}$ ).

It must be stressed that the low $X / R$ ratio applies only to branches in the LV microgrid since, in this work, transformers in grid-connected mode are not modelled in the LV microgrid.

Therefore, high DG and microgeneration penetration will require the development of an effective voltage control scheme based on active and reactive power control since the decoupling between active power and voltage is not valid in $L V$ networks. In the case of $L V$ grids with microgeneration, the possibility of controlling active power injected by microgeneration units has to be envisaged, since

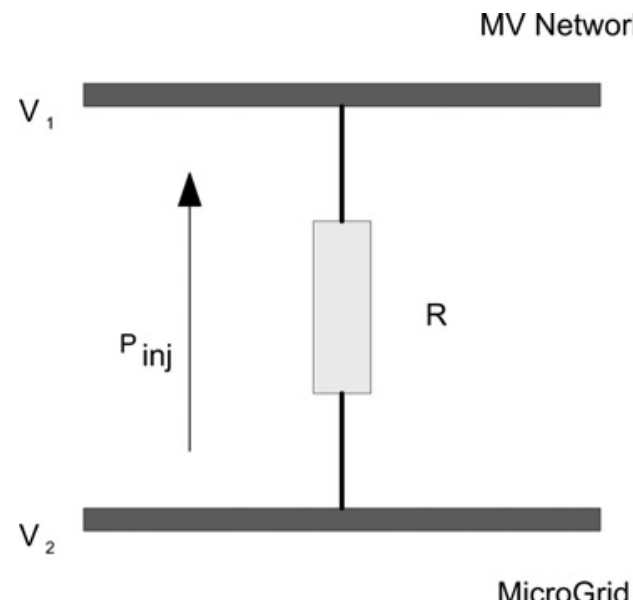

Figure 2 Example system this is the most effective way of controling voltage at the LV level under these conditions.

In this paper, a new voltage control procedure is proposed that includes optimising operating conditions by using DG, installed at the MV level, microgrid and OLTC transformer control capabilities. In multi-microgrid systems, it is necessary to address the problem of voltage control at both the MV and the LV levels. To ensure a coordinated operation, a global voltage control algorithm will run at the MV level and the solution obtained will be tested at the LV microgrid level in order to evaluate its feasibility. This approach requires a sequence of global problem solutions and local sub-problem solutions in order to converge to a near-optimum solution.

The voltage control system is designed to be a real-time application that helps the DSO to efficiently manage the distribution network. This proposed functionality comprises a preliminary stage, where several studies are performed offline in order to evaluate the performance of the algorithm given the characteristics of the network and adequately select the parameters for the optimisation problem formulation. Only then, the optimisation tool may be used in real-time operation and made available to the operator.

\subsection{Mathematical formulation}

The voltage control problem for multi-microgrid systems is a non-linear optimisation problem that can be formulated as shown in (2).

$\min \mathrm{OF}(\underline{X})$

subject to

$$
\begin{aligned}
V_{i}^{\min } & \leq V_{i} \leq V_{i}^{\max } \\
S_{i k}^{\min } & \leq S_{i k} \leq S_{i k}^{\max } \\
t_{i}^{\min } & \leq t_{i} \leq t_{i}^{\max } \\
Q_{i}^{\min } & \leq Q_{i} \leq Q_{i}^{\max }
\end{aligned}
$$

where $O F$ is the objective function, $X$ is the control variables, $V_{i}$ is the voltage at bus $i, V_{i}^{\min }, V_{i}^{\max }$ are the minimum and maximum voltage at bus $i, S_{i k}$ is the power flow in branch $i k, S_{i k}^{\min }, S_{i k}^{\max }$ are the minimum and maximum power flows in branch $i k, t_{i}$ is the transformer tap of or capacitor step position and $t_{i}^{\min }, t_{i}^{\max }$ are the minimum and maximum tap.

The objective function chosen aims at minimising active power losses and microgeneration shedding and is shown in (3).

$$
\min \sum P_{\text {loss }}+\sum \mu G_{\text {shed }}
$$

where $P_{\text {loss }}$ is the active power losses and $\mu G_{\text {shed }}$ is the amount of microgeneration shed.

Active power losses were assessed as a function of the line resistance and the current flowing in each line after a power 
flow routine. The total active power losses used in the objective function are calculated as the sum of the active power losses in each line.

\subsection{Optimisation algorithm}

Given the characteristics of the problem under analysis, with a large dimension and a mixed continuous/integer nature concerning the control variables (possibility of controlling active and reactive generation levels - continuous variables, and transformer taps/capacitor banks - integer variables), a meta-heuristic approach was chosen. The optimisation algorithm used in this work was evolutionary particle swarm optimization (EPSO). This algorithm is a combination of traditional particle swarm intelligence, developed by Kennedy and Eberhardt [13], and evolutionary strategies, developed by Schwefel [14], and has been used extensively in optimisation problems for electrical power systems. More details on the algorithm can be found in $[15,16]$.

The variables or parameters in EPSO are divided into object parameters (the $X$ variables - control parameters of the problem) and strategic parameters (the weights $w$ ). The algorithm considers a set of solutions or alternatives that are called particles. The $X$ variables include all the control variables used in the voltage and reactive power control optimisation problem, as described in Section 3.1. Strategic parameters $(w)$ are used to control the behaviour of the optimisation algorithm.

In EPSO, each particle (or solution at a given stage) is defined by its position $X_{i}^{k}$ and velocity $v_{i}^{k}$ for the coordinate position $i$ and particle $k$.

The general scheme of EPSO is presented next:

- Replication - each particle is replicated $r$ times.

- Mutation - each particle has its weights $w$ mutated.

- Reproduction - each particle generates an offspring according to the particle movement rule.

- Evaluation - each offspring has its fitness evaluated.

- Selection - the best particles are selected by stochastic tournament.

The particle movement rule is the following: given a particle $X_{i}$, a new particle $\mathrm{X}_{i}^{\text {new }}$ can be obtained from (4).

$$
X_{i}^{\text {new }}=X_{i}+v_{i}^{\text {new }}
$$

with

$$
v_{i}^{\text {new }}=w_{i 0}^{*} V_{i}+w_{i 1}^{*}\left(b_{i}-X_{i}\right)+w_{i 2}^{*}\left(b_{\mathrm{g}}^{*}-X_{i}\right)
$$

where $X_{i}$ is the position of the particle, $v_{i}$ is the velocity of the particle, $w_{i k}^{*}$ is the strategic parameter (weight), $b_{i}$ is the best solution of each particle and $b_{\mathrm{g}}^{*}$ is the best solution among all particles.

The weights $\left(w_{i k}^{*}\right)$ are mutated as shown in (6).

$$
w_{i k}^{*}=w_{i k}+\tau N(0,1)
$$

where $\tau$ is the fixed learning parameter and $N(0,1)$ is the random variable with Gaussian distribution, 0 mean and variance 1 .

The global best $\left(b_{\mathrm{g}}^{*}\right)$ is also mutated as shown in (7).

$$
b_{\mathrm{g}}^{*}=b_{\mathrm{g}}+\tau^{\prime} N(0,1)
$$

where $\tau^{\prime}$ is the fixed learning parameter.

The control variables used in this work were:

- Reactive power from DG sources.

- Active power from microgrids by means of microgeneration shedding (assuming that all microsources are curtailed in the same proportion).

- Reactive power from microgrids by means of capacitor banks located at the MV/LV transformer substation of each microgrid.

- OLTC transformer settings at distribution transformers.

These control variables are used as set-points sent to each device (DG unit, microgrid or OLTC transformer) using the control scheme presented in Fig. 1. For instance, considering the active power of microgeneration, a set-point is sent to the MGCC indicating that microgeneration should be reduced according to that set-point. This information is then sent to individual microsource controllers (as defined in the control structure presented in [10]) that receive an individual set-point in order to lower their generation.

In this work, the constraints were dealt with in traditional evolutionary strategies, that is, using a penalty approach.

\subsection{Artificial neural network}

As previously mentioned, the voltage control scheme presented is intended to be used as an online function, made available to the DSO. Therefore, and in order to speed up the control algorithm, an artificial neural network (ANN) able to emulate the behaviour of the LV network (or microgrid) was included. This option enables the use of the meta-heuristic tool employed in real-time operation, reducing the long simulation times that were required in order to calculate consecutive LV power flows. In fact, the ANN is used to provide a steady-state equivalent of the microgrid, avoiding in this way the extension of the load flow analysis to the LV microgrid level. Using the ANN, the computational burden and consequently the computational time have significantly decreased. 
The ANN to be employed has the following inputs:

- Voltage at the MV/LV substation.

- Active power generated by each microgenerator unit.

- Total load of the microgrid.

The two outputs are the active power losses and the maximum voltage inside the microgrid, since one of the most critical problems to be addressed is related with overvoltage problems that may occur.

To achieve good performance, different ANN topologies (different number of layers and number of neurons in each hidden layer) were tested. The ANN with the best performance has eight inputs, one hidden layer with 24 neurons and two outputs.

To generate the data set corresponding to the inputs chosen to train the ANN, a large number of power flows were computed, considering different combinations of the inputs (i.e. several values for the voltage reference at the $\mathrm{MV} / \mathrm{LV}$ substation, for the power generated by each microsource and for the load) in order to calculate the active power losses and assess the voltage profiles in each scenario.

The generated data set contains 11664 operating points, which were split into a training set and a test set containing $2 / 3$ and $1 / 3$ of the total operating points, respectively. The training set was used for training the ANN and the test set for performance evaluation purposes. The MATLAB Neural Network Toolbox using the Levenberg-Marquart back-propagation algorithm was used to identify the ANN parameters.

The performance obtained can be evaluated in terms of the mean absolute error (MAE). The MAE obtained for one of the outputs (active power losses) was $1.01 \times 10^{-3}$. Despite the simple structure adopted for the ANN, the performance parameters illustrated the quality of the tool for emulating the behaviour of the microgrid.

Nevertheless, in case of microgrid reconfiguration (due to adding of a new microgenerator, for instance), a new ANN must be computed. This means that it is necessary to update the data for the power flow and then generate a new data set and train a new ANN that emulates the LV microgrid steady-state behaviour.

\section{Test case networks and scenarios}

To test the voltage control approach developed, two real distribution networks were used: an MV distribution network and an LV distribution network shown in Figs. 3 and 4 , respectively.

The MV network used is a rural network with two distinct areas with different voltage levels: $30 \mathrm{kV}$ at node NO119 and

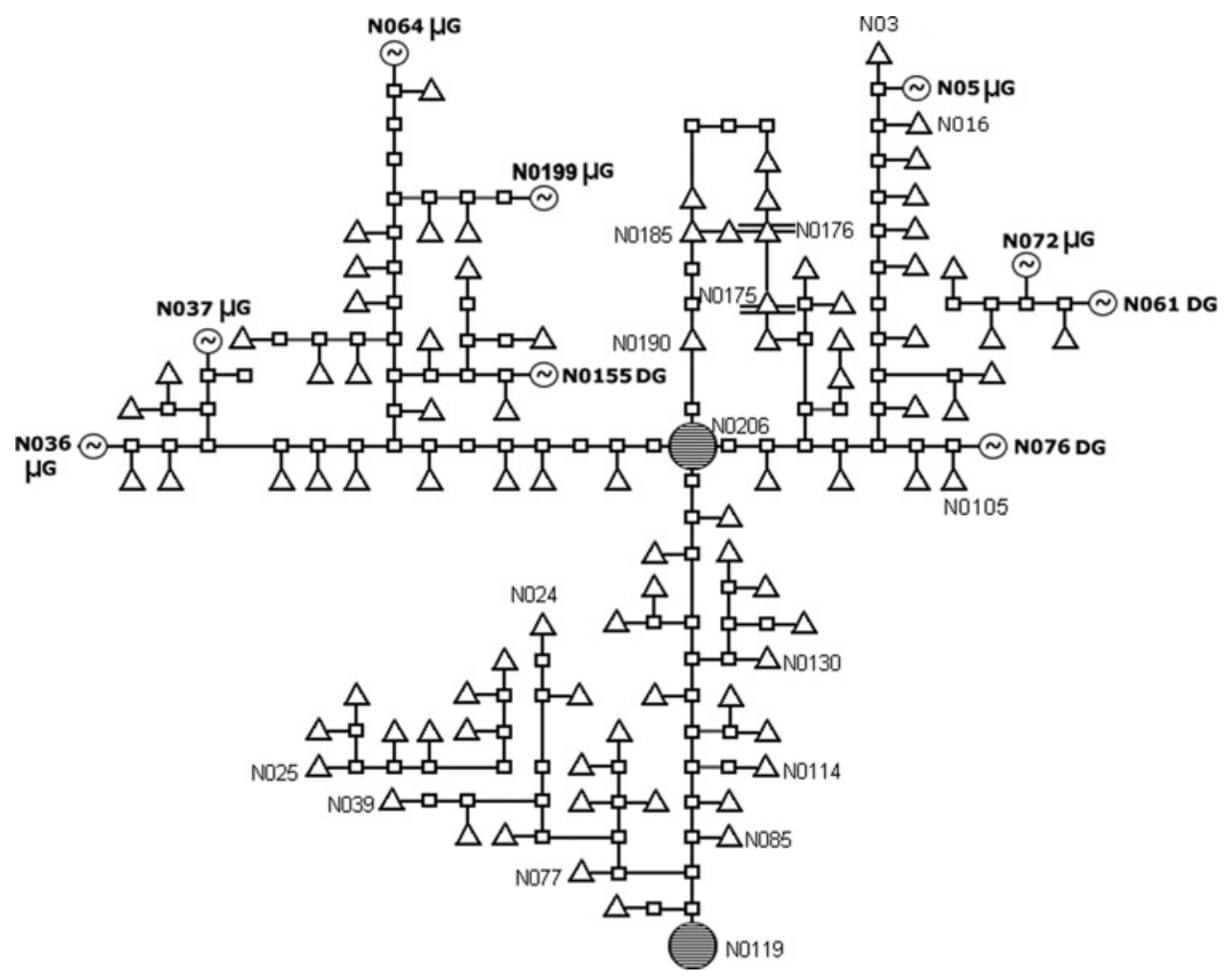

Figure 3 MV test network 


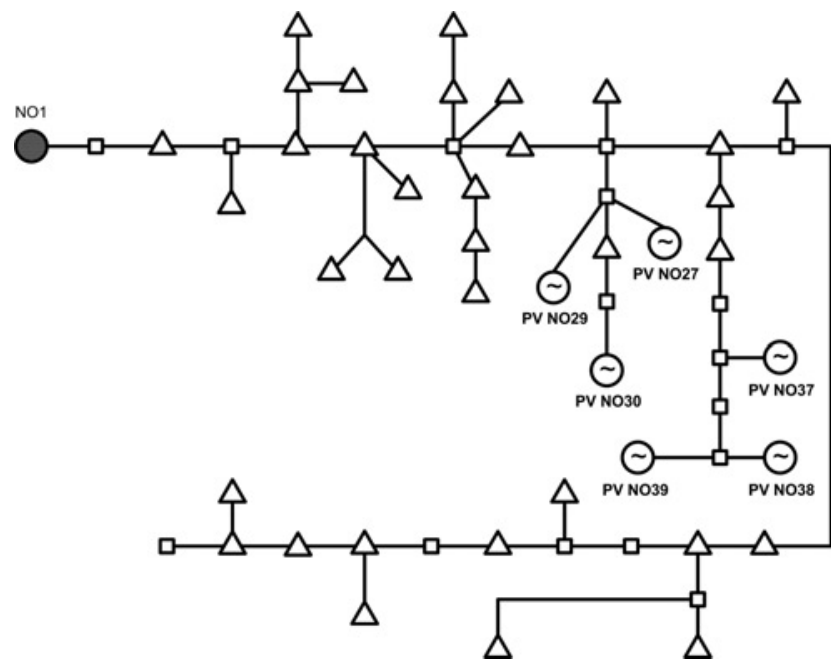

Figure $4 \mathrm{LV}$ test network

$15 \mathrm{kV}$ after the $30 \mathrm{kV} / 15 \mathrm{kV}$ transformer at node NO206. It comprises six microgrids (marked as $\mu \mathrm{G}$ in Fig. 3), all with a similar topology, and 3 DG units (marked as DG in Fig. 3) based on Combined Heat and Power - CHP (NO3 in Fig. 3) and wind (NO16 and N061 in Fig. 3).

The LV network (microgrid) used is also a rural network with a radial structure. It was considered that all microgrids have the same structure (shown in Fig. 4). As previously stated, this LV network was used to train the ANN that was included in the optimisation algorithm.

Data on the test networks used in this work are presented in Tables 2-5.

Each microgrid is supposed to comprise six microgenerators, all photovoltaic units (marked as $\mathrm{PV}$ in Fig. 4). The ANN is, however, capable of dealing with different levels of microgeneration penetration, as well as with different locations for the microsources.
Table 1 Test case scenarios for generation

\begin{tabular}{|l|c|c|}
\hline \multirow{2}{*}{$\begin{array}{c}\text { Test } \\
\text { network }\end{array}$} & \multicolumn{2}{|c|}{ Distributed generation/microgeneration } \\
\cline { 2 - 3 } & $\begin{array}{c}\text { Installed capacity, } \\
\text { MW }\end{array}$ & $\begin{array}{c}\text { Percentage peak } \\
\text { load, \% }\end{array}$ \\
\hline MV & 3.6 & 60 \\
\hline LV & 0.1 & 100 \\
\hline
\end{tabular}

In this approach, from the MV point of view, each LV microgrid was considered as a single bus with an equivalent generator (corresponding to the sum of all micro-source generations) and equivalent load (corresponding to the sum of all LV loads).

Typical generation curves for each generating technology (CHP, Wind and PV) were used, as well as typical load curves, for a $24 \mathrm{~h}$ period.

The total generation installed capacity for the scenarios used is presented in Table 1.

The $24 \mathrm{~h}$ profile of the total load (a mix of residential and commercial consumers) in the MV network is presented in Fig. 5.

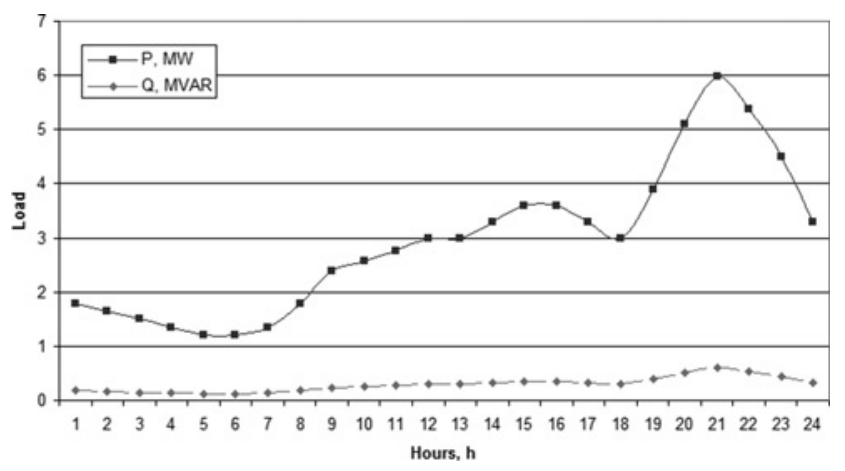

Figure $5 \mathrm{MV}$ test network total load

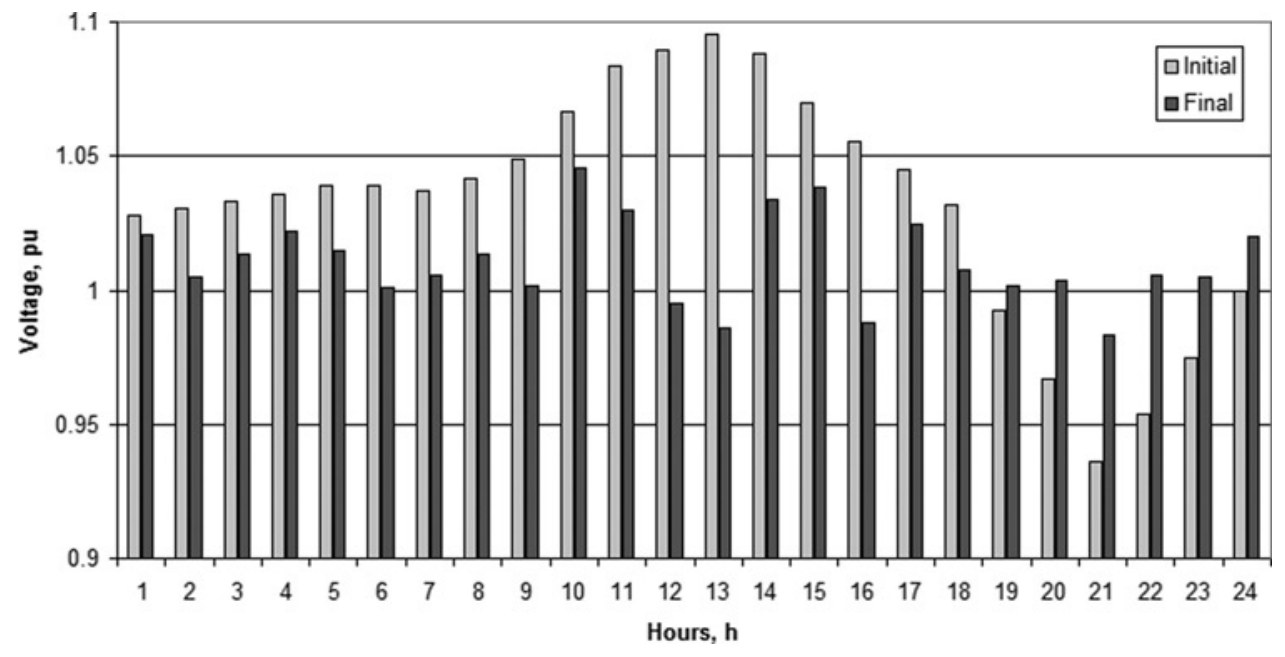

Figure 6 Maximum voltage values in microgrid at node 64 


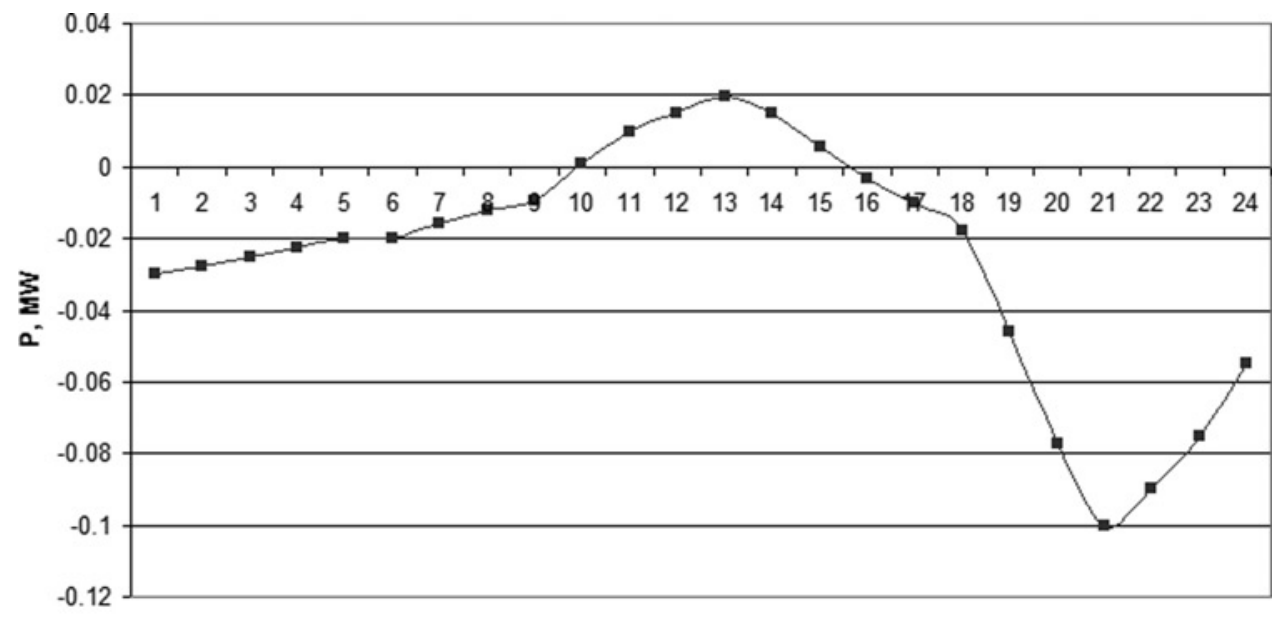

Hours, h

Figure 7 Active power exported to the MV network by the microgrid at node 64

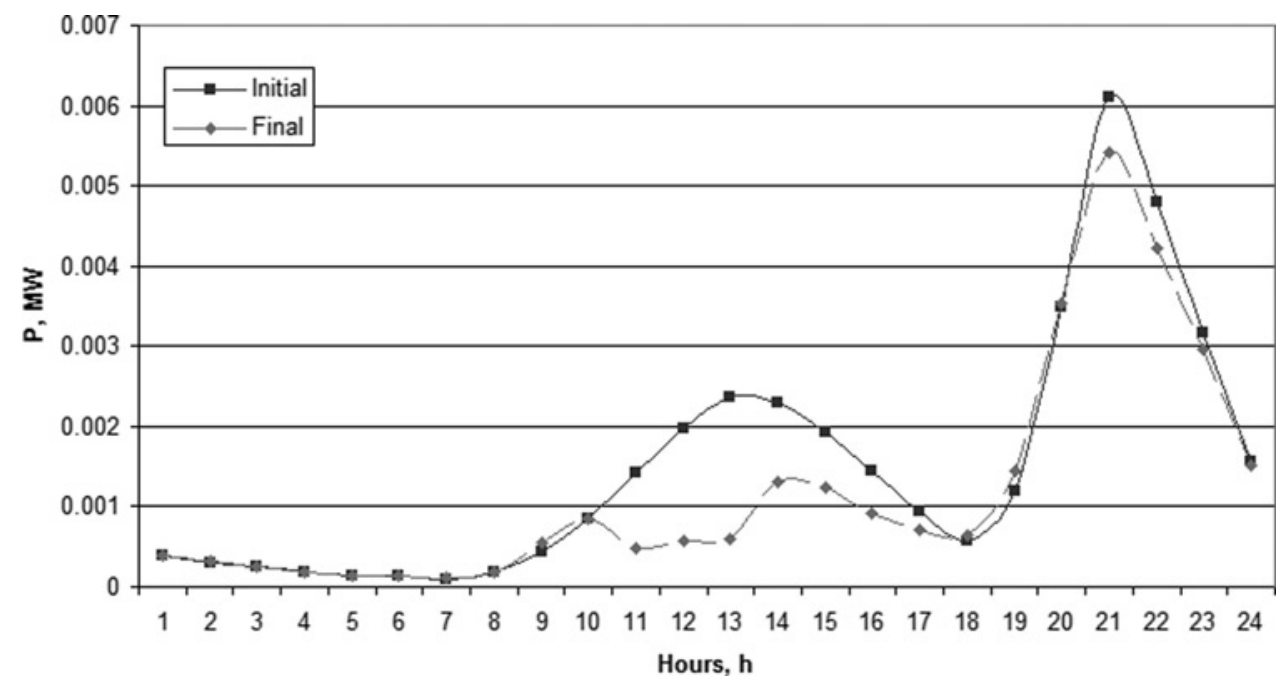

Figure 8 Active power losses in microgrid at node 64

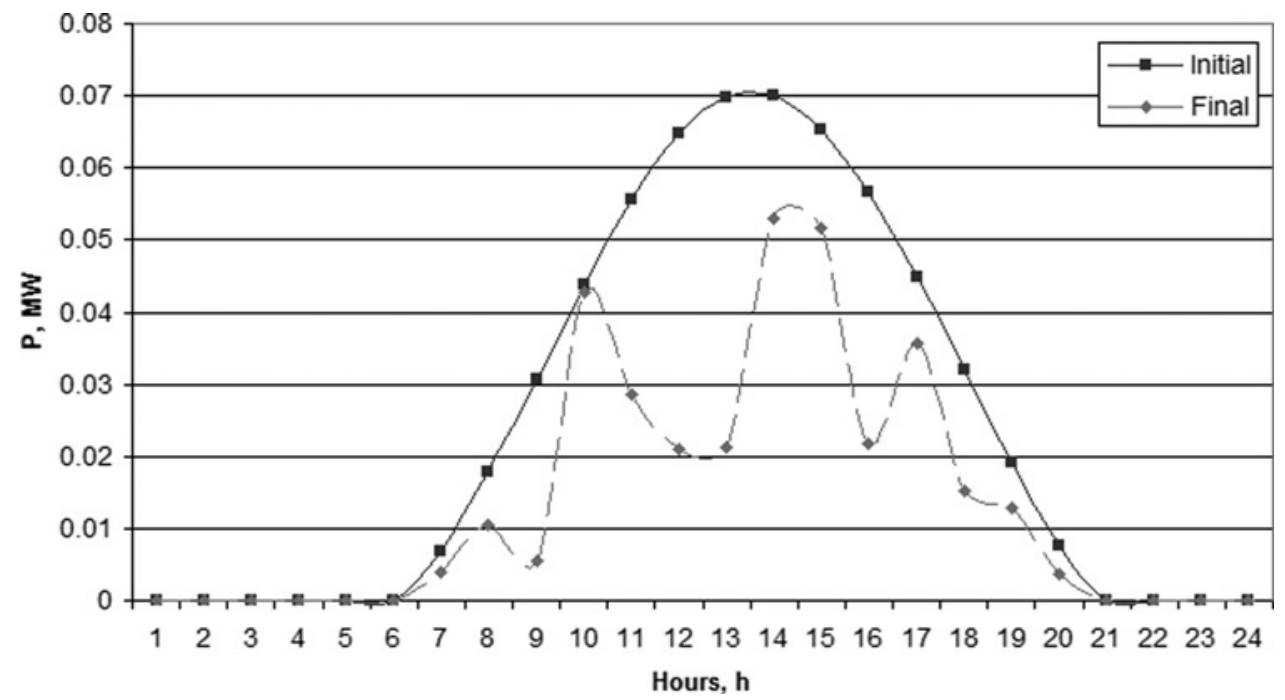

Figure 9 Total microgeneration in microgrid at node 64 


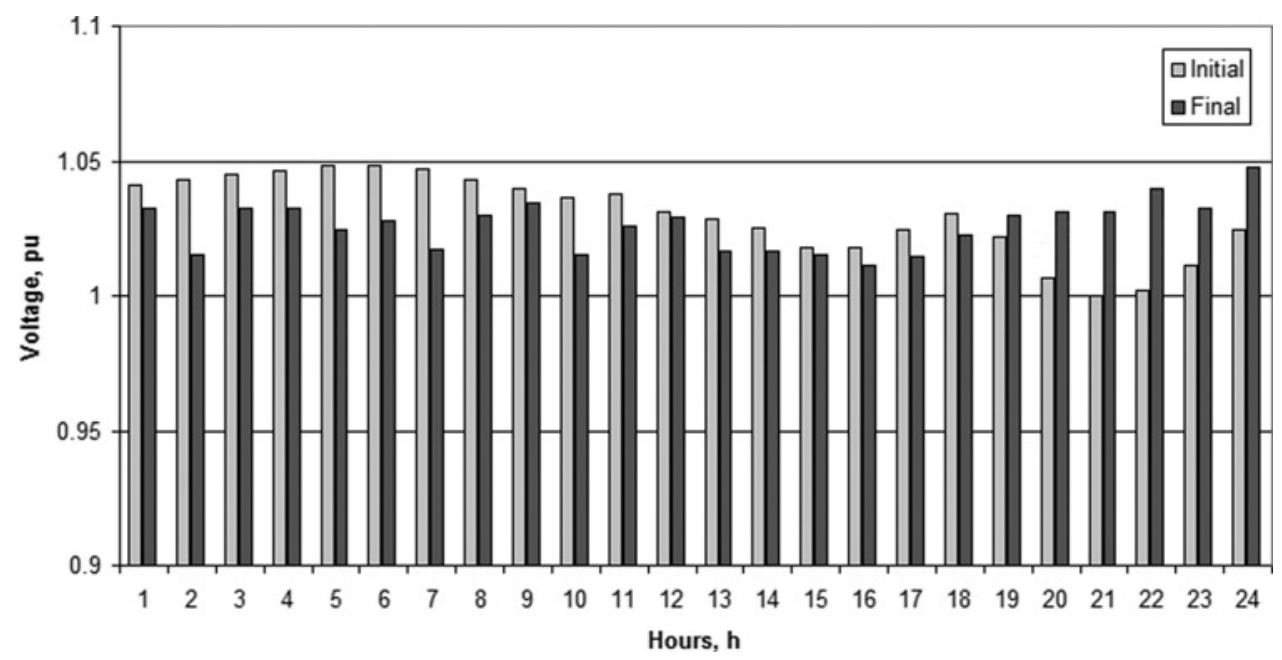

Figure 10 Maximum voltage values in the MV network

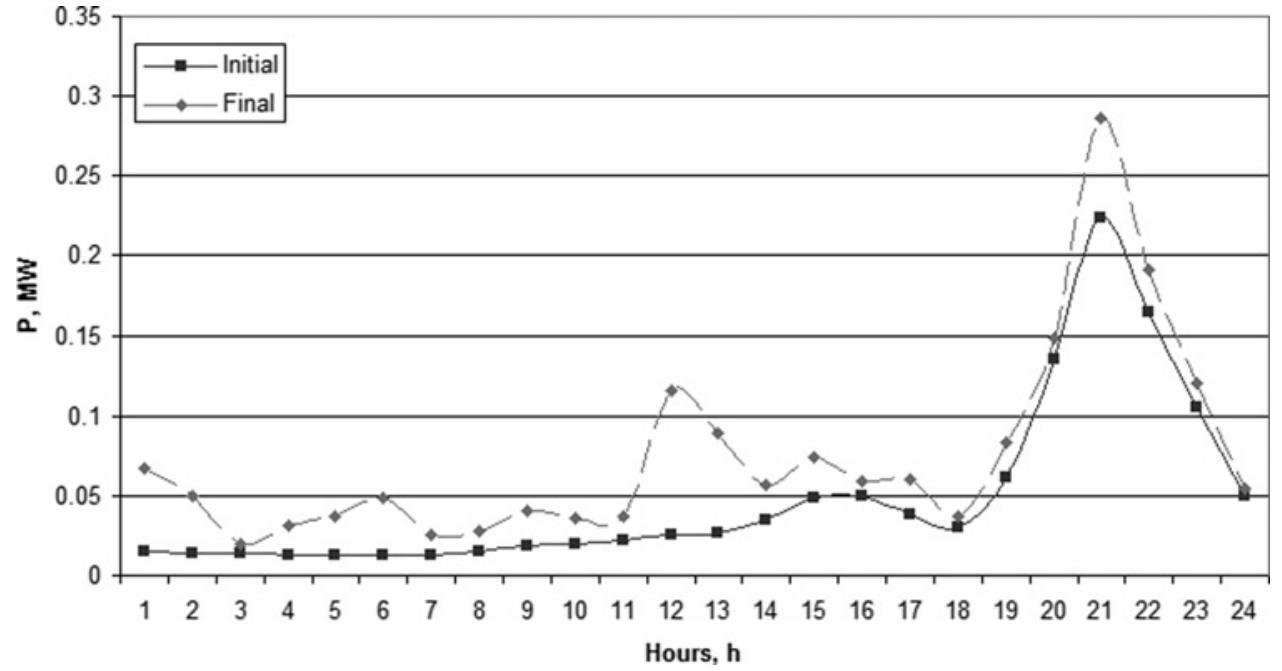

Figure 11 Active power losses in the MV network

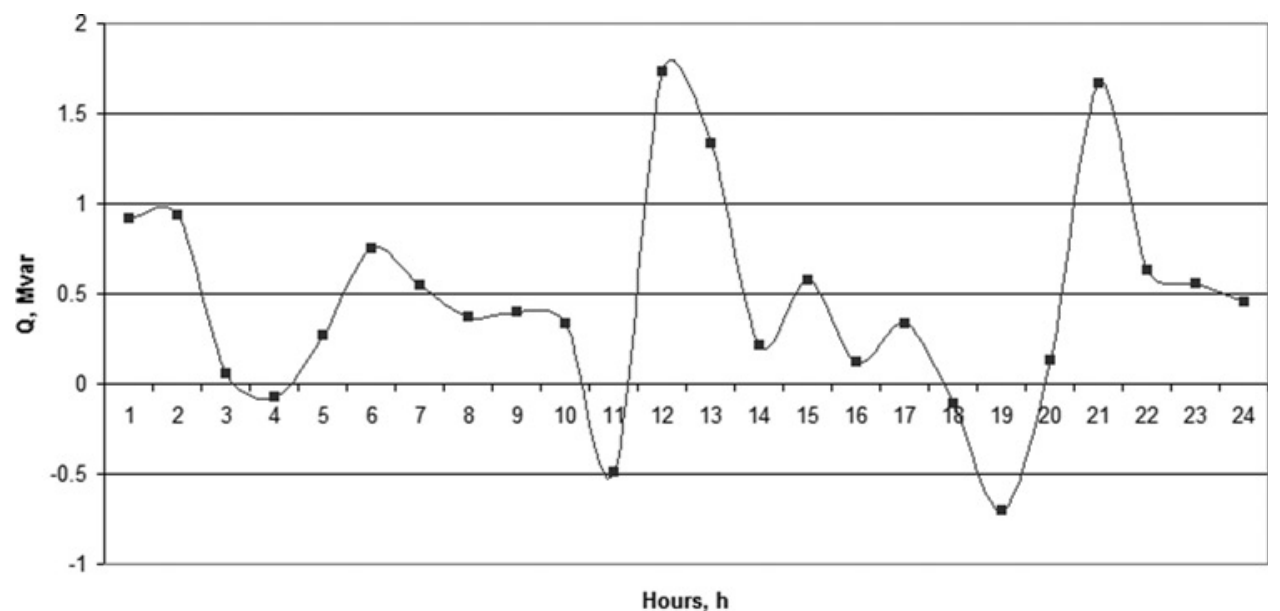

Figure 12 Total reactive power provided by DG and microgeneration 
Table 2 LV test network line data

\begin{tabular}{|c|c|c|c|c|}
\hline From bus & To bus & Length, $\mathrm{m}$ & $R, \mathrm{ohm} / \mathrm{km}$ & $L, \mathrm{mH} / \mathrm{km}$ \\
\hline NO1 & $\mathrm{NO} 2$ & 16 & 0.164 & 0.22 \\
\hline NO2 & NO3 & 23 & 0.32 & 0.23 \\
\hline NO3 & NO4 & 25 & 0.443 & 0.25 \\
\hline NO4 & NO5 & 3 & 3.08 & 0.44 \\
\hline NO4 & NO6 & 24 & 0.443 & 0.25 \\
\hline NO6 & NO7 & 22 & 1.2 & 0.27 \\
\hline NO7 & NO8 & 5 & 3.08 & 0.44 \\
\hline NO7 & NO9 & 25 & 12.6 & 0.32 \\
\hline NO6 & N010 & 22 & 0.443 & 0.25 \\
\hline N010 & N011 & 15 & 3.08 & 0.44 \\
\hline N010 & N012 & 12 & 3.08 & 0.44 \\
\hline N010 & N013 & 13 & 3.08 & 0.44 \\
\hline NO10 & N014 & 29 & 0.443 & 0.25 \\
\hline N014 & N015 & 9 & 3.08 & 0.32 \\
\hline N014 & N016 & 27 & 1.2 & 0.27 \\
\hline N016 & N017 & 3 & 3.08 & 0.44 \\
\hline N014 & N018 & 2 & 3.08 & 0.44 \\
\hline N018 & N019 & 3 & 3.08 & 0.44 \\
\hline NO19 & NO20 & 4 & 3.08 & 0.44 \\
\hline N014 & NO21 & 19 & 0.443 & 0.25 \\
\hline NO21 & NO22 & 17 & 0.443 & 0.25 \\
\hline NO22 & NO23 & 12 & 0.868 & 0.24 \\
\hline NO22 & NO24 & 34 & 0.443 & 0.25 \\
\hline NO24 & NO25 & 26 & 0.868 & 0.24 \\
\hline NO24 & NO26 & 6 & 3.08 & 0.44 \\
\hline NO24 & NO27 & 15 & 3.08 & 0.44 \\
\hline NO24 & NO28 & 24 & 1.2 & 0.27 \\
\hline NO27 & NO29 & 13 & 3.08 & 0.44 \\
\hline NO22 & NO30 & 3 & 0.443 & 0.25 \\
\hline NO30 & NO31 & 2 & 3.08 & 0.44 \\
\hline NO30 & NO32 & 12 & 0.443 & 0.25 \\
\hline NO32 & NO33 & 24 & 0.443 & 0.25 \\
\hline NO33 & NO34 & 22 & 3.08 & 0.32 \\
\hline NO34 & NO35 & 54 & 3.08 & 0.32 \\
\hline NO35 & NO36 & 61 & 3.08 & 0.32 \\
\hline
\end{tabular}

Continued
Table 2 Continued

\begin{tabular}{|l|c|c|c|c|}
\hline From bus & To bus & Length, $\mathrm{m}$ & $R$, ohm $/ \mathrm{km}$ & $L, \mathrm{mH} / \mathrm{km}$ \\
\hline NO36 & NO37 & 7 & 3.08 & 0.32 \\
\hline NO32 & NO38 & 30 & 0.443 & 0.25 \\
\hline NO38 & NO39 & 12 & 1.2 & 0.27 \\
\hline NO38 & NO40 & 23 & 0.443 & 0.25 \\
\hline NO40 & NO41 & 33 & 0.443 & 0.25 \\
\hline NO41 & NO42 & 51 & 1.2 & 0.27 \\
\hline NO41 & NO43 & 126 & 1.2 & 0.27 \\
\hline NO41 & NO44 & 90 & 0.443 & 0.25 \\
\hline NO44 & NO45 & 15 & 3.08 & 0.32 \\
\hline NO44 & NO46 & 33 & 0.443 & 0.25 \\
\hline NO46 & NO47 & 54 & 0.443 & 0.25 \\
\hline NO47 & NO48 & 33 & 3.08 & 0.32 \\
\hline NO47 & NO49 & 40 & 0.443 & 0.25 \\
\hline NO49 & NO50 & 30 & 0.443 & 0.25 \\
\hline NO50 & NO51 & 30 & 1.2 & 0.27 \\
\hline NO50 & NO52 & 188 & 0.641 & 0.26 \\
\hline
\end{tabular}

\section{Results and discussion}

This control algorithm was implemented in the MATLAB environment, using MATPOWER [17] to calculate the power flows and MATLAB Neural Network Toolbox to design the ANN.

The objective function for the optimisation problem aimed at reducing active power losses while maintaining voltage profiles within admissible limits $( \pm 5 \%)$.

For the optimisation algorithm, a maximum of 100 iterations were used for each hour of the day for a total time horizon of one day. Typical $24 \mathrm{~h}$ curves for each generation technology and for the load (considered similar in all load nodes) have been developed for that purpose.

The control variables used are presented in (8).

$$
P_{\mu \mathrm{G} 1}|\ldots| P_{\mu \mathrm{G} 6}\left|Q_{\mu \mathrm{G} 1}\right| \ldots\left|Q_{\mu \mathrm{G} 6}\right| Q_{\mathrm{DG} 1}|\ldots| Q_{\mathrm{DG} 3} \mid t_{\text {tap }}
$$

where $P_{\mu \mathrm{G} i}$ is the active power generated by microgrid $i$, $Q_{\mu \mathrm{G} i}$ is the reactive power generated by microgrid $i, Q_{\mathrm{DG} i}$ is the reactive power generated by DG unit $i$ and $t_{1 \text { tap }}$ is the tap value in the transformer at node 206.

The main results obtained are presented in the following figures. 
Table 3 LV test network bus data

\begin{tabular}{|c|c|}
\hline Bus no. & Load, kVA \\
\hline NO3 & 6.9 \\
\hline NO5 & 31.05 \\
\hline NO6 & 6.9 \\
\hline NO7 & 10.35 \\
\hline NO8 & 6.9 \\
\hline NO9 & 10.35 \\
\hline N010 & 3.45 \\
\hline N011 & 27.6 \\
\hline N012 & 6.9 \\
\hline N013 & 6.9 \\
\hline N015 & 6.9 \\
\hline N016 & 10.35 \\
\hline N017 & 6.9 \\
\hline N018 & 3.45 \\
\hline N019 & 3.45 \\
\hline NO20 & 6.9 \\
\hline NO21 & 34.5 \\
\hline NO23 & 13.8 \\
\hline NO25 & 20.7 \\
\hline NO26 & 13.8 \\
\hline NO27 & 6.9 \\
\hline NO28 & 13.8 \\
\hline NO29 & 24.15 \\
\hline NO30 & 10.35 \\
\hline N031 & 13.8 \\
\hline NO32 & 3.45 \\
\hline NO33 & 17.25 \\
\hline NO34 & 10.35 \\
\hline NO35 & 20.7 \\
\hline NO36 & 3.45 \\
\hline NO37 & 6.9 \\
\hline NO39 & 20.7 \\
\hline NO40 & 10.35 \\
\hline NO41 & 10.35 \\
\hline NO42 & 20.7 \\
\hline
\end{tabular}

Continued
Table 3 Continued

\begin{tabular}{|l|c|}
\hline NO43 & 41.5 \\
\hline NO45 & 10.35 \\
\hline N046 & 10.35 \\
\hline N047 & 10.35 \\
\hline NO48 & 6.9 \\
\hline N049 & 10.35 \\
\hline NO50 & 10.35 \\
\hline N051 & 10.35 \\
\hline
\end{tabular}

Fig. 6 compares the base situation without the voltage control functionality (Initial) and the result obtained after the application of the control algorithm (Final) in the LV microgrid. It can be seen that the voltage values were out of the admissible range of $\pm 5 \%$ due to the massive penetration of PV-based microgeneration that generated power outside peak demand hours.

Fig. 7 shows that the microgrid exports power to the upstream network between 10 and $16 \mathrm{~h}$ (sunny hours) and imports in the remaining hours, including during peak load at $21 \mathrm{~h}$. Nevertheless, the voltage control functionality succeeded in bringing the voltages back into the admissible range, either during daytime when voltages were too high or during night-time when voltages were low.

In addition, active power losses (Fig. 8) in the microgrid are reduced since some microgeneration shedding (Fig. 9) was required during the sunniest hours in order to bring voltage profiles back within admissible limits. The high losses in the base case (Initial in Fig. 8) are due to the fact that microgeneration penetration was extremely high regarding the local load level and the location of the microgeneration was not ideal.

Concerning the MV network, it may be observed in Fig. 10 that voltage values were inside admissible values, despite the fact that the control algorithm had to raise voltages during night-time in order to be able to also raise voltage within the microgrids (Fig. 6).

Fig. 11 shows that the MV network losses have increased slightly, which is natural given that the main concern in this network was poor voltage profiles.

Fig. 12 presents the evolution of reactive power generated (positive values) or absorbed (negative values) by the DG sources and the microgrids in order to aid voltage control. The base case (Initial) is not shown since it considered a unity power factor for all generating sources. 
Table 4 MV test network line data

\begin{tabular}{|c|c|c|c|c|}
\hline From bus & To bus & Length, m & $R, \mathrm{ohm} / \mathrm{km}$ & $L, \mathrm{mH} / \mathrm{km}$ \\
\hline NO206 & NO202 & 68 & 0.324 & 0.10 \\
\hline NO200 & NO206 & 666 & 0.521 & 0.38 \\
\hline NO206 & NO201 & 71 & 0.324 & 0.10 \\
\hline NO206 & NO203 & 50 & 0.324 & 0.10 \\
\hline N0118 & N0119 & 842 & 0.521 & 0.38 \\
\hline N0176 & N0174 & 490 & 0.324 & 0.10 \\
\hline N0175 & N0176 & 90 & 0.324 & 0.10 \\
\hline N0176 & N0182 & 262 & 0.627 & 0.11 \\
\hline N0131 & N0133 & 27 & 0.731 & 0.39 \\
\hline N0132 & N0122 & 756 & 0.731 & 0.39 \\
\hline NO29 & NO30 & 323 & 0.731 & 0.39 \\
\hline NO62 & NO58 & 604 & 0.731 & 0.39 \\
\hline NO79 & NO77 & 46 & 0.731 & 0.39 \\
\hline N057 & NO56 & 481 & 1.181 & 0.40 \\
\hline N0189 & N0192 & 100 & 1.608 & 0.41 \\
\hline N0184 & N0182 & 236 & 0.324 & 0.10 \\
\hline NO44 & NO45 & 661 & 1.181 & 0.40 \\
\hline N0111 & N0104 & 474 & 0.324 & 0.12 \\
\hline NO134 & N0135 & 119 & 1.181 & 0.40 \\
\hline NO201 & N0190 & 1349 & 0.731 & 0.39 \\
\hline NO190 & N0187 & 183 & 0.463 & 0.10 \\
\hline NO162 & N0163 & 105 & 0.731 & 0.39 \\
\hline NO194 & NO208 & 1364 & 1.643 & 0.41 \\
\hline NO110 & N0114 & 2 & 0.561 & 0.40 \\
\hline N0175 & N0171 & 210 & 0.627 & 0.11 \\
\hline N0168 & N0171 & 325 & 1.608 & 0.41 \\
\hline N0185 & N0191 & 250 & 0.568 & 0.11 \\
\hline N0193 & N0191 & 54 & 0.463 & 0.10 \\
\hline NO75 & NO74 & 217 & 0.731 & 0.39 \\
\hline N0183 & N0178 & 64 & 1.181 & 0.40 \\
\hline NO147 & N0149 & 20 & 0.733 & 0.41 \\
\hline N0138 & N0139 & 35 & 0.568 & 0.11 \\
\hline NO90 & N086 & 163 & 0.731 & 0.39 \\
\hline NO23 & NO24 & 539 & 1.608 & 0.41 \\
\hline NO65 & NO73 & 528 & 1.181 & 0.40 \\
\hline
\end{tabular}

Continued
Table 4 Continued

\begin{tabular}{|c|c|c|c|c|}
\hline From bus & To bus & Length, m & $R, \mathrm{ohm} / \mathrm{km}$ & $L, \mathrm{mH} / \mathrm{km}$ \\
\hline N0112 & N0105 & 406 & 1.608 & 0.41 \\
\hline NO48 & NO51 & 758 & 0.731 & 0.39 \\
\hline N097 & NO80 & 1066 & 0.731 & 0.39 \\
\hline NO44 & NO34 & 634 & 0.731 & 0.39 \\
\hline NO88 & N089 & 13 & 0.731 & 0.39 \\
\hline NO88 & NO64 & 1552 & 0.731 & 0.39 \\
\hline NO31 & NO36 & 1177 & 0.731 & 0.39 \\
\hline N0106 & NO92 & 1058 & 1.181 & 0.40 \\
\hline NO78 & NO63 & 1404 & 1.608 & 0.41 \\
\hline NO204 & NO209 & 613 & 0.731 & 0.39 \\
\hline NO204 & NO205 & 41 & 0.731 & 0.39 \\
\hline N014 & N013 & 10 & 1.181 & 0.40 \\
\hline N0156 & N0158 & 1310 & 0.731 & 0.39 \\
\hline N015 & N016 & 21 & 0.731 & 0.39 \\
\hline NO38 & NO37 & 199 & 1.643 & 0.41 \\
\hline N068 & N066 & 669 & 0.731 & 0.39 \\
\hline N068 & N061 & 555 & 0.731 & 0.39 \\
\hline N0107 & N0109 & 10 & 1.181 & 0.40 \\
\hline N0196 & N0199 & 480 & 0.568 & 0.11 \\
\hline NO120 & N0121 & 9 & 1.608 & 0.41 \\
\hline N0127 & N0130 & 172 & 1.181 & 0.40 \\
\hline NO40 & NO42 & 12 & 0.731 & 0.39 \\
\hline NO46 & NO49 & 696 & 0.731 & 0.39 \\
\hline N0161 & N0180 & 812 & 1.181 & 0.40 \\
\hline N0161 & N0160 & 10 & 1.181 & 0.40 \\
\hline N0151 & N0150 & 64 & 0.568 & 0.13 \\
\hline N069 & N060 & 1227 & 0.731 & 0.39 \\
\hline N0166 & N0169 & 38 & 1.181 & 0.40 \\
\hline NO55 & NO53 & 1217 & 0.731 & 0.39 \\
\hline NO75 & N081 & 399 & 0.731 & 0.39 \\
\hline NO129 & N0128 & 275 & 1.181 & 0.40 \\
\hline N0167 & N0170 & 56 & 1.181 & 0.40 \\
\hline N0185 & N0174 & 536 & 0.532 & 0.11 \\
\hline N090 & N096 & 682 & 0.731 & 0.39 \\
\hline N031 & NO28 & 594 & 0.731 & 0.39 \\
\hline
\end{tabular}


Table 4 Continued

\begin{tabular}{|c|c|c|c|c|}
\hline From bus & To bus & Length, m & $R, \mathrm{ohm} / \mathrm{km}$ & $L, \mathrm{mH} / \mathrm{km}$ \\
\hline N0100 & N0101 & 11 & 1.181 & 0.40 \\
\hline N0100 & NO84 & 1006 & 0.731 & 0.39 \\
\hline N094 & N085 & 711 & 0.731 & 0.39 \\
\hline N012 & NO4 & 2234 & 0.731 & 0.39 \\
\hline N012 & NO2 & 1561 & 0.731 & 0.39 \\
\hline N010 & N017 & 638 & 0.731 & 0.39 \\
\hline NO162 & N0144 & 1073 & 1.608 & 0.41 \\
\hline N0103 & N091 & 649 & 1.608 & 0.41 \\
\hline NO8 & NO7 & 42 & 1.181 & 0.40 \\
\hline NO11 & NO9 & 681 & 0.731 & 0.39 \\
\hline N0153 & N0164 & 699 & 0.731 & 0.39 \\
\hline N0153 & N0155 & 245 & 1.181 & 0.40 \\
\hline N0112 & N076 & 2286 & 1.608 & 0.41 \\
\hline NO83 & NO82 & 1833 & 0.731 & 0.39 \\
\hline N0148 & N0141 & 343 & 1.181 & 0.40 \\
\hline N0140 & N0154 & 821 & 1.181 & 0.40 \\
\hline N0198 & NO207 & 1218 & 0.731 & 0.39 \\
\hline N0173 & N0172 & 136 & 1.181 & 0.40 \\
\hline NO41 & NO39 & 176 & 1.608 & 0.41 \\
\hline N018 & N019 & 924 & 0.731 & 0.39 \\
\hline NO8 & NO1 & 2520 & 0.731 & 0.39 \\
\hline NO26 & NO25 & 3 & 0.324 & 0.12 \\
\hline N0126 & N0123 & 167 & 0.731 & 0.39 \\
\hline NO32 & NO33 & 257 & 0.731 & 0.39 \\
\hline NO157 & N0167 & 703 & 0.731 & 0.39 \\
\hline N0197 & N0195 & 10 & 0.731 & 0.39 \\
\hline NO6 & NO5 & 394 & 1.181 & 0.40 \\
\hline NO52 & NO54 & 272 & 1.181 & 0.40 \\
\hline NO3 & NO6 & 436 & 0.731 & 0.39 \\
\hline N069 & NO71 & 82 & 0.731 & 0.39 \\
\hline N0181 & N0184 & 154 & 0.324 & 0.10 \\
\hline N0186 & N0185 & 94 & 0.463 & 0.10 \\
\hline N0145 & NO143 & 63 & 1.181 & 0.40 \\
\hline $\mathrm{NO} 22$ & NO20 & 407 & 0.919 & 0.39 \\
\hline N0125 & NO124 & 30 & 1.181 & 0.40 \\
\hline
\end{tabular}

Table 4 Continued

\begin{tabular}{|c|c|c|c|c|}
\hline From bus & To bus & Length, $\mathrm{m}$ & $R, \mathrm{ohm} / \mathrm{km}$ & $L, \mathrm{mH} / \mathrm{km}$ \\
\hline NO6 & N015 & 1188 & 0.411 & 0.38 \\
\hline NO10 & NO8 & 515 & 1.181 & 0.40 \\
\hline N011 & N010 & 302 & 1.181 & 0.40 \\
\hline N018 & N011 & 1114 & 1.181 & 0.40 \\
\hline N014 & N012 & 330 & 0.731 & 0.39 \\
\hline NO21 & N014 & 977 & 0.731 & 0.39 \\
\hline N015 & NO29 & 2412 & 0.411 & 0.38 \\
\hline NO21 & N018 & 594 & 1.181 & 0.40 \\
\hline NO27 & NO21 & 1114 & 1.181 & 0.40 \\
\hline NO27 & NO22 & 1394 & 0.919 & 0.39 \\
\hline NO22 & NO23 & 610 & 1.608 & 0.41 \\
\hline NO41 & NO26 & 2688 & 0.731 & 0.39 \\
\hline NO29 & NO32 & 518 & 0.411 & 0.38 \\
\hline NO48 & N031 & 3460 & 0.731 & 0.39 \\
\hline NO32 & NO42 & 952 & 0.411 & 0.38 \\
\hline NO38 & N035 & 138 & 0.731 & 0.39 \\
\hline NO43 & NO38 & 320 & 0.731 & 0.39 \\
\hline NO43 & NO44 & 735 & 1.181 & 0.40 \\
\hline NO50 & NO43 & 1536 & 0.731 & 0.39 \\
\hline NO47 & NO27 & 3422 & 0.919 & 0.39 \\
\hline NO47 & No41 & 1460 & 1.608 & 0.41 \\
\hline N055 & NO47 & 2024 & 0.919 & 0.39 \\
\hline NO50 & NO48 & 1798 & 0.731 & 0.39 \\
\hline NO52 & NO50 & 204 & 0.731 & 0.39 \\
\hline NO57 & N052 & 879 & 0.731 & 0.39 \\
\hline NO70 & N055 & 1589 & 0.919 & 0.39 \\
\hline N078 & N057 & 1476 & 0.731 & 0.39 \\
\hline NO49 & NO59 & 2060 & 0.411 & 0.38 \\
\hline NO59 & NO83 & 1449 & 0.411 & 0.38 \\
\hline NO59 & N062 & 454 & 0.731 & 0.39 \\
\hline N062 & N065 & 550 & 0.731 & 0.39 \\
\hline N065 & N067 & 379 & 0.731 & 0.39 \\
\hline N067 & N068 & 175 & 0.731 & 0.39 \\
\hline NO75 & N069 & 847 & 0.731 & 0.39 \\
\hline NO79 & N070 & 605 & 0.919 & 0.39 \\
\hline
\end{tabular}


Table 4 Continued

\begin{tabular}{|c|c|c|c|c|}
\hline From bus & To bus & Length, $\mathrm{m}$ & $R, \mathrm{ohm} / \mathrm{km}$ & $L, \mathrm{mH} / \mathrm{km}$ \\
\hline NO70 & N075 & 466 & 0.731 & 0.39 \\
\hline N099 & NO78 & 1380 & 0.731 & 0.39 \\
\hline N093 & N079 & 1377 & 0.919 & 0.39 \\
\hline NO83 & N087 & 536 & 0.411 & 0.38 \\
\hline N087 & N090 & 395 & 0.731 & 0.39 \\
\hline N087 & N0131 & 3561 & 0.411 & 0.38 \\
\hline N093 & N094 & 1177 & 0.521 & 0.38 \\
\hline NO118 & N093 & 5019 & 0.521 & 0.38 \\
\hline N094 & N097 & 1100 & 0.521 & 0.38 \\
\hline N097 & N098 & 60 & 0.521 & 0.38 \\
\hline N098 & N0110 & 872 & 0.919 & 0.39 \\
\hline N098 & N0102 & 2643 & 0.521 & 0.38 \\
\hline N099 & N0103 & 1494 & 0.731 & 0.39 \\
\hline N0106 & N099 & 712 & 0.731 & 0.39 \\
\hline NO102 & N0100 & 102 & 0.731 & 0.39 \\
\hline NO102 & N0107 & 839 & 0.521 & 0.38 \\
\hline NO103 & N0108 & 954 & 0.731 & 0.39 \\
\hline N0115 & N0106 & 935 & 0.731 & 0.39 \\
\hline NO107 & N0117 & 1521 & 0.521 & 0.38 \\
\hline NO108 & N0134 & 1714 & 1.608 & 0.41 \\
\hline N0108 & N0116 & 2589 & 0.731 & 0.39 \\
\hline N0118 & N0111 & 738 & 0.919 & 0.39 \\
\hline NO132 & N0112 & 1891 & 1.608 & 0.41 \\
\hline NO125 & N0115 & 1261 & 0.731 & 0.39 \\
\hline N0116 & N0140 & 1559 & 1.181 & 0.40 \\
\hline N0116 & N0120 & 1698 & 0.731 & 0.39 \\
\hline N0117 & N0165 & 5165 & 0.521 & 0.38 \\
\hline N0117 & N0127 & 745 & 1.181 & 0.40 \\
\hline NO120 & N0126 & 913 & 0.731 & 0.39 \\
\hline NO166 & N0125 & 2295 & 0.731 & 0.39 \\
\hline N0126 & N0129 & 457 & 1.608 & 0.41 \\
\hline NO127 & N0152 & 1511 & 1.181 & 0.40 \\
\hline NO129 & N0136 & 268 & 1.608 & 0.41 \\
\hline NO131 & N0137 & 669 & 0.411 & 0.38 \\
\hline NO137 & N0132 & 517 & 1.608 & 0.41 \\
\hline
\end{tabular}

Continued
Table 4 Continued

\begin{tabular}{|c|c|c|c|c|}
\hline From bus & To bus & Length, $\mathrm{m}$ & $R, \mathrm{ohm} / \mathrm{km}$ & $L, \mathrm{mH} / \mathrm{km}$ \\
\hline N0134 & N0142 & 494 & 1.608 & 0.41 \\
\hline N0136 & N0156 & 1363 & 1.608 & 0.41 \\
\hline N0136 & N0113 & 3080 & 0.731 & 0.39 \\
\hline N0173 & N0137 & 3436 & 0.411 & 0.38 \\
\hline N0146 & N0138 & 634 & 0.731 & 0.39 \\
\hline N0140 & N0148 & 405 & 1.181 & 0.40 \\
\hline N0142 & N0153 & 1009 & 0.731 & 0.39 \\
\hline N0142 & N0146 & 180 & 1.608 & 0.41 \\
\hline N0148 & N0145 & 61 & 1.181 & 0.40 \\
\hline N0146 & N0147 & 68 & 1.608 & 0.41 \\
\hline N0152 & N0151 & 231 & 1.181 & 0.40 \\
\hline N0152 & N0161 & 536 & 1.181 & 0.40 \\
\hline N0156 & N0189 & 1611 & 1.608 & 0.41 \\
\hline N0179 & N0159 & 1117 & 0.731 & 0.39 \\
\hline N0159 & N0168 & 364 & 1.608 & 0.41 \\
\hline N0159 & N0162 & 161 & 0.731 & 0.39 \\
\hline N0165 & NO204 & 2069 & 0.731 & 0.39 \\
\hline N0165 & N0197 & 2090 & 0.521 & 0.38 \\
\hline N0177 & N0166 & 453 & 0.731 & 0.39 \\
\hline N0168 & N0167 & 516 & 1.181 & 0.40 \\
\hline N0179 & N0173 & 364 & 0.411 & 0.38 \\
\hline N0183 & N0177 & 195 & 0.731 & 0.39 \\
\hline N0194 & N0179 & 625 & 0.411 & 0.38 \\
\hline NO203 & N0183 & 1872 & 0.731 & 0.39 \\
\hline N0187 & N0186 & 13 & 0.532 & 0.11 \\
\hline N0189 & N0196 & 548 & 1.181 & 0.40 \\
\hline N0188 & N0193 & 482 & 0.870 & 0.11 \\
\hline NO202 & N0194 & 1144 & 0.411 & 0.38 \\
\hline N0197 & N0198 & 97 & 0.521 & 0.38 \\
\hline N0198 & NO200 & 817 & 0.521 & 0.38 \\
\hline N0113 & N095 & 988 & 0.731 & 0.39 \\
\hline N095 & NO88 & 387 & 0.731 & 0.39 \\
\hline NO42 & NO49 & 2311 & 0.411 & 0.38 \\
\hline N0181 & N0188 & 152 & 1.376 & 0.12 \\
\hline N067 & N072 & 243 & 0.731 & 0.39 \\
\hline
\end{tabular}


Table $5 \mathrm{MV}$ test network bus data

\begin{tabular}{|c|c|}
\hline Bus no. & Load, kVA \\
\hline N0176 & 630 \\
\hline N0133 & 100 \\
\hline NO122 & 50 \\
\hline NO30 & 100 \\
\hline N058 & 100 \\
\hline NO77 & 50 \\
\hline N056 & 250 \\
\hline N0192 & 100 \\
\hline N0182 & 125 \\
\hline NO45 & 25 \\
\hline NO104 & 0 \\
\hline N0135 & 50 \\
\hline NO190 & 630 \\
\hline N0163 & 100 \\
\hline NO208 & 30 \\
\hline N0114 & 1335 \\
\hline N0171 & 100 \\
\hline N0191 & 630 \\
\hline NO74 & 160 \\
\hline N0178 & 50 \\
\hline N0149 & 500 \\
\hline N0139 & 1000 \\
\hline NO86 & 25 \\
\hline NO24 & 100 \\
\hline NO73 & 100 \\
\hline N0105 & 100 \\
\hline N051 & 160 \\
\hline NO80 & 100 \\
\hline NO34 & 100 \\
\hline N089 & 100 \\
\hline NO64 & 50 \\
\hline NO36 & 100 \\
\hline N092 & 250 \\
\hline N063 & 160 \\
\hline NO209 & 100 \\
\hline
\end{tabular}

Continued
Table 5 Continued

\begin{tabular}{|c|c|}
\hline Bus no. & Load, kVA \\
\hline NO205 & 250 \\
\hline N013 & 100 \\
\hline N0158 & 100 \\
\hline N016 & 100 \\
\hline NO37 & 15 \\
\hline N066 & 200 \\
\hline N061 & 160 \\
\hline N0109 & 100 \\
\hline N0199 & 160 \\
\hline N0121 & 100 \\
\hline N0130 & 100 \\
\hline NO40 & 50 \\
\hline NO46 & 100 \\
\hline N0180 & 100 \\
\hline N0160 & 100 \\
\hline N0150 & 630 \\
\hline NO60 & 100 \\
\hline N0169 & 50 \\
\hline N0175 & 160 \\
\hline N053 & 160 \\
\hline N081 & 250 \\
\hline NO128 & 100 \\
\hline NO170 & 200 \\
\hline N0174 & 400 \\
\hline N096 & 75 \\
\hline NO28 & 50 \\
\hline N0101 & 50 \\
\hline NO84 & 50 \\
\hline N085 & 100 \\
\hline NO4 & 100 \\
\hline NO2 & 100 \\
\hline NO17 & 50 \\
\hline NO144 & 100 \\
\hline N091 & 100 \\
\hline NO7 & 100 \\
\hline
\end{tabular}

Continued 
Table 5 Continued

\begin{tabular}{|l|c|}
\hline \multicolumn{1}{|c|}{ Bus no. } & Load, kVA \\
\hline NO9 & 100 \\
\hline NO164 & 100 \\
\hline NO155 & 0 \\
\hline NO76 & 100 \\
\hline NO82 & 100 \\
\hline NO141 & 50 \\
\hline NO154 & 100 \\
\hline NO207 & 100 \\
\hline NO172 & 100 \\
\hline NO39 & 25 \\
\hline NO19 & 100 \\
\hline NO1 & 100 \\
\hline NO25 & 100 \\
\hline NO123 & 530 \\
\hline NO33 & 160 \\
\hline NO157 & 100 \\
\hline NO195 & 250 \\
\hline NO5 & 100 \\
\hline NO54 & 250 \\
\hline NO3 & 160 \\
\hline NO71 & 160 \\
\hline NO184 & 100 \\
\hline NO185 & 100 \\
\hline NO143 & 100 \\
\hline NO20 & 100 \\
\hline NO124 & 100 \\
\hline NO72 & 100 \\
\hline
\end{tabular}

\section{Conclusion}

Voltage/VAR control in distribution systems integrating microgrids can be treated as a hierarchical optimisation problem that must be analysed in a coordinated way between $L V$ and MV levels.

Given the characteristics of the LV networks, both active and reactive power control is needed for an efficient voltage control scheme.

An optimisation algorithm based on a meta-heuristic was adopted in order to deal with the voltage/VAR control problem at the MV level. The algorithm has proved to be efficient in achieving the main objective function - voltage profile control and active power losses reduction.

The ANN used to emulate the behaviour of the LV microgrid proved to have good performance, enabling reduction of the computational time considerably. The combination of the meta-heuristic optimisation motor together with an ANN equivalent representation of the microgrid allows the use of this approach for real time under DMS environments.

\section{Acknowledgments}

This work was supported in part by the European Commission within the framework of the More MicroGrids project, Contract no. 019864 - (SES6). The authors would like to thank the research team of the More MicroGrids project for valuable discussions and feedback.

A. G. Madureira wants to express his gratitude to Fundação para a Ciência e a Tecnologia (FCT), Portugal, for supporting this work under grant SFRH/BD/29459/2006.

\section{References}

[1] Joós G., OOI B.T., MCGILLIS D., GALIANA F.D., MARCEAU R.: 'The potential of distributed generation to provide ancillary services'. Proc. IEEE PES Summer Meeting, Seattle, USA, July 2000, pp. $1762-1767$

[2] VOVOS P.N., KIPRAKIS A.E., WALLACE A.R., HARRISON G.P.: 'Centralized and distributed voltage control: impact on distributed generation penetration', IEEE Trans. Power Syst., 2007, 1, (22), pp. 476-483

[3] KUlmala A., RePO S., JÄrVEnTAUSTA P.: 'Active voltage level management of distribution networks with distributed generation using on load tap changing transformers'. Proc. IEEE Power Tech., Lausanne, Switzerland, July 2007, pp. $455-460$

[4] CALdON C., TURRI R., PRANDONI V., SPELTA S.: 'Control issues in MV distribution systems with large-scale integration of distributed generation'. Proc. Bulk Power System Dynamics and Control - VI, Cortina d'Ampezzo, Italy, August 2004, pp. 583-589

[5] NIKNAM T., RANJBAR A., SHIRANI A.: 'Impact of distributed generation on volt/var control in distribution networks'. Proc. IEEE Power Tech., Bologna, Italy, June 2003, pp. 1-6

[6] PEÇAS LOPES J.A., MENDONÇA A., FONSECA N., SECA L.: 'Voltage and reactive power control provided by DG units'. Proc. CIGRE Symp. Power Systems with Dispersed Generation, Athens, Greece, April 2005, pp. 13-16 
[7] Jenkins N., ALLAN R., CROSSley P., KIRSCHEN D., STRBAC G.: 'Embedded generation' (IEE Power and Energy Series 31, Inst. Elect. Eng, 2000)

[8] MASTERS C.L.: 'Voltage rise: the big issue when connecting embedded generation to long $11 \mathrm{kV}$ overhead lines', Power Eng. J., 2002, 1, (16), pp. 5-12

[9] MAdUREIRA A.G., PEÇAS LOPES J.A.: 'Voltage and reactive power control in MV networks integrating microGrids'. Proc. Int. Conf. Renewable Energy Power Quality, Seville, Spain, March 2007, ICREPQ Webpage: http://www.icrepq. com/icrepq07/386-madureira.pdf

[10] PeÇAS lopes J.A., MOREIRA C.L., MAdUREIRA A.G.: 'Defining control strategies for microGrids islanded operation', IEEE Trans. Power Syst., 2006, 2, (21), pp. 916-924

[11] PeÇAS LOPES J.A., MOREIRA C.L., MAdUReIRA A.G., et AL.: 'Control strategies for microGrids emergency operation'. Proc. Int. Conf. Future Power Syst., Amsterdam, The Netherlands, November 2005, pp. 1-6
[12] MicroGrids Webpage: http://microgrids.power.ece. ntua.gr/micro/index.php, accessed June 2008

[13] KENNEDY J., EBERHART R.C.: 'Particle swarm optimization'. IEEE Int. Conf. Neural Networks, Perth, Australia, November 1995, pp. 1942-1948

[14] SCHWEFEL H.P.: 'Evolution and optimum seeking' (Wiley, 1995)

[15] MIRANDA V., FONSECA N.: 'EPSO - Evolutionary particle swarm optimization, a new algorithm with applications in power systems'. Proc. IEEE Trans. Distribution Conf. Exhibition, October 2002, pp. 6-10

[16] MIRANDA V., FONSECA N.: 'New evolutionary particle swarm algorithm (EPSO) applied to voltage/VAR control'. Proc. Power Syst. Comput. Conf., Seville, Spain, June 2002, pp. 1-6

[17] MATPOWER Webpage: http://www.pserc.cornell.edu/ matpower/, accessed June 2008 